\title{
MODEL ASSESSMENT OF INLET TIMING SYSTEM IMPACT ON CYLINDER INDICATED PRESSURE COURSE OF PISTON PNEUMATIC ENGINE
}

\author{
Dariusz Szpica, Michal Korbut \\ Bialystok University of Technology, Poland \\ d.szpica@pb.edu.pl, korbutmichal@gmail.com
}

\begin{abstract}
Continuous tightening of the exhaust gas toxicity standards emitted from transport means results in the necessity of the combustion process modification and search for alternative propulsion sources. There are many design solutions for the pneumatic engines, i.e. piston, rotary or unconventional. The most popular type of the pneumatic engines is piston engines based on the internal combustion engines. In the case of these engines, the main problem is the peak cylinder pressure and the mean indicated pressure, which are responsible for external indicators, such as torque and power, as well as economic air consumption. In a significant part, the piston pneumatic engine is built on the basis of the internal combustion engine, modifying the compression ratio and the camshaft timing to adapt it to compressed air operation. It is also important that the pressure at the end of the compression stroke should not be higher than the compressed air supply pressure. In order to optimize the indicated pressure, the timing system should be adjusted adequately. The article concerns the selection of the operating phase of the pneumatic engine inlet valve, specifically the opening angle with respect to the top dead centre. The mathematical description of the mechanical part is based on a piston machine, while the pneumatic part is based on a lumped element method. The numerical calculations indicated that the appropriate configuration of the inlet valve opening allows to achieve a high level of the mean indicated pressure and consequently a high torque value generated by the engine can be expected. During each analysis, the air consumption was additionally assessed. Appropriate selection of the inlet valve opening allows to eliminate the effect of "wrapping" the pressure, which decreases the external indicators of the engine and increases the load on the piston-connecting rod-crankshaft elements.
\end{abstract}

Keywords: mechanical engineering, pneumatic engine, modelling.

\section{Introduction}

Recent legal regulations regarding the approval of vehicles, in particular driving tests to assess the exhaust emissions: the World Harmonized Light Vehicle Test Procedure (WLTP) [1] and the Real Driving Emissions (RDE) [2], significantly reduce the possibility of using only the internal combustion engines in the powertrain systems. A separate group is constituted by the non-road engines, where also legal regulations are applied [3;4]. Despite the continuous evolution of the internal combustion engine and the improvement of the combustion process organisation [5-10], it is difficult to decrease the toxicity of exhaust emissions. Reduced-carbon fuels [11-14], or systems to assist the internal combustion engines by creating the hybrid drives $[15 ; 16]$ can be used. Electric drives are becoming increasingly popular [17], also the interest in the hydraulic/pneumatic drive is growing [18]. Th eelectric and hydraulic/pneumatic drives do not directly emit exhaust emissions, however, they move the emissions to the places where the power source is produced. $\mathrm{H}_{2}$ fuel $[19 ; 20]$ is regarded as the drive of the future, although the storage and distribution of this type of fuel is still a problem.

Analysing the design solutions of the pneumatic motors, they can be classified into:

- Piston engine [21;22];

- Vane engine $[23 ; 24]$;

- Rotary engine [25];

- Unconventional - Di Pietro [26].

Commercial pneumatic engines can be found in the offer of companies, such as Mdi [27] or Engine air [28]. The MDi company has launched a series of cars with the pneumatic drive and Engine air is constantly working on improving the efficiency of the pneumatic engines.

In many cases, the prototype pneumatic engine solutions are based on the internal combustion piston engines [29-31], the main purpose of this is to decrease the production costs. In addition, the base in the form of an internal combustion engine, in terms of strength, will withstand the loads resulting from the supply of compressed air, which rarely exceeds $10 \mathrm{e} 5 \mathrm{~Pa}$. Experimental tests of the pneumatic engines are modelled on the internal combustion engines beyond the exhaust emission assessment. The performance and economic parameters are evaluated. Detailed analysis of the 
economic and energetic indicators is presented in $[32 ; 33]$, where nevertheless, the low efficiency of the pneumatic engine was demonstrated.

The mathematical modelling describing the operation of the pneumatic engine concentrates on the flow through the local drag and the air exchange in the cylinder. The mechanical part of the engine, especially of a piston engine, is a description based on a piston machine used in the modelling internal combustion engines [34]. In the paper [25], the mathematical modelling process used ready-made subsystems of the Matlab environment, demonstrating the compatibility of model and experimental runs for transition states ofthe rotary engine. In many cases, the values of the engine indicators are based on the averaged values over the operating cycle. In the paper [35], the analysis of the piston pneumatic engine operation is presented in reference to one work cycle, which may be the basis for the strength calculations of the operating elements.

The paper presents the next stage of the analysis of the pneumatic engine operation initiated in [36]. This time the focus was on the influence of the inlet valve opening angle on the pressure indicated in the cylinder, which is related to the engine torque.

\section{Materials and methods}

The object of the analysis was a single-cylinder engine. The engine was based on a two-stroke Jawa 50 piston engine [36]. It was adapted to be supplied with compressed air after certain modifications (Fig. 1):

- the original fuel system was abandoned by blocking the intake tract with the plate 1 (Fig. 1) the crankcase operation as a pump is not required;

- instead of the spark plug, a solenoid valve 2 was installed to supply the compressed air - the ignition system is redundant;

- the operation of the crankcase as a pump was blocked by mounting a washer 3 ;

- between the cylinder head and the cylinder the distance plate 4 was mounted to decrease the compression ratio - leaving the original compression ratio would cause the pressure at the end of the compression to be close to the supply pressure;

- the engine crankcase was connected to the gearbox lubrication system by making holes in the housing.

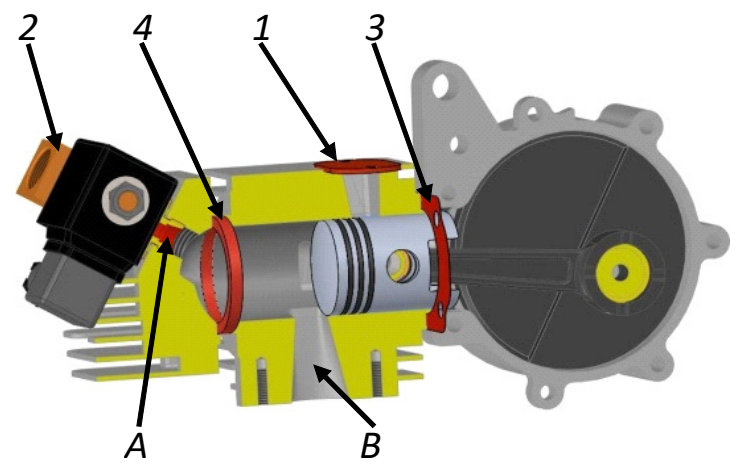

Fig.1. Subject of modelling (description in the main text)

The engine operates like a two-stroke engine and its basic technical data are presented in Table 1. During the crankshaft rotation at the end of the compression stroke around the top dead centre (TDC), the solenoid valve 2 (Fig. 1) opens and supplies compressed air to the cylinder through the hole $A$. The working stroke starts and continues until the outlet window $B$ is opened before the bottom dead centre (BDC). Then the cycle repeats. An important parameter affecting the operation of the engine is the inlet valve opening $(I V O)$, which should not block the compression process and be in a position that prevents air from releasing through the outlet window with the solenoid valve open.

The mathematical model was built on the basis of available literature sources [35; 37-39]. Using the functional diagram, Fig 2, the mathematical description was divided into mechanical and pneumatic parts. 
Engine basic technical data

\begin{tabular}{|r|c|c|r|}
\hline \multicolumn{1}{|c|}{ Parameter } & Glossary & Unit & \multicolumn{1}{|c|}{ Value } \\
\hline number of cylinders & $N$ & - & 1 \\
\hline timing system (max. throughput): inlet & $(\mu A)_{\text {in }}$ & $\mathrm{m}^{2}$ & $12.723 \mathrm{e}-6$ \\
outlet & $(\mu A)_{\text {out }}$ & $\mathrm{m}^{2}$ & $238.400 \mathrm{e}-6$ \\
\hline displacement / volume & $V_{c}$ & $\mathrm{~m}^{3}$ & $0.5479 \mathrm{e}-6$ \\
\hline bore & $D$ & $\mathrm{~m}$ & $40.000 \mathrm{e}-3$ \\
\hline stroke & $S$ & $\mathrm{~m}$ & $43.600 \mathrm{e}-3$ \\
\hline connecting rod length & $L$ & $\mathrm{~m}$ & $100.000 \mathrm{e}-3$ \\
\hline compression ratio & $\mathcal{E}$ & - & $6: 1$ \\
\hline weight of the components involved in the reciprocal motion & $m_{A}$ & $\mathrm{~kg}$ & 0.142 \\
\hline crankshaft mass moment of inertia & $J_{c}$ & $\mathrm{~kg} \cdot \mathrm{m}^{2}$ & 0.140 \\
\hline $\begin{array}{r}\text { substitute mass of the part of the connecting rod rotating on } \\
\text { radius } R \text { of the } x \text {-th crank }\end{array}$ & $m_{B}$ & $\mathrm{~kg}$ & 0.140 \\
\hline
\end{tabular}

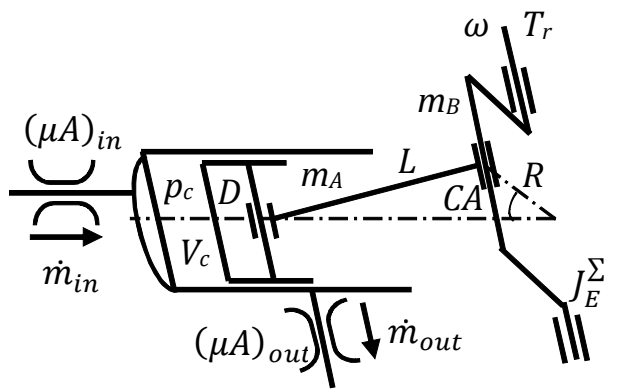

Fig. 2. Scheme of the mechanical and pneumatic subsystem (description in the main text)

The following simplifications were adopted in the mechanical part:

- the torque transfer system was perfectly stiff;

- the influence of elastic vibrations was omitted;

- the energy flow flowed without loss;

- the pressure course depended on the timing and input and output pressure, as well as the position of the piston;

- the moment of inertia of the crankshaft and flywheel were omitted at angular velocity analysis.

The engine torque dependence of the crankshaft angle degrees $(C A)$ under established conditions could be presented:

$$
T_{r}=R A_{p} S(C A) p_{c}(C A)-R^{2} m_{A} S(C A)(\cos (C A)+\lambda \cos (2 C A)) \omega^{2}
$$

where $\omega$ - angular crankshaft speed, $\mathrm{rad} \cdot \mathrm{s}^{-1}$; glossary - see Table1 and Table2;

For a single-cylinder two-stroke engine, the $S(C A)$ function adopted the form:

$$
S(C A)=\frac{\lambda \sin (2 C A)}{2-\lambda^{2} \sin ^{2}(C A)}+\sin (C A)
$$

Calculated from (1) torque $T_{r}$ was the indicated torque, and its value of the mean indicated torque $M I T$ allowed to determine the mean indicated pressure $(M I P)$ :

$$
M I P=\frac{2 \pi M I T}{V_{c}}
$$

The indicated moment with the consideration of the mechanical resistance, mainly lost to defeat the frictional resistances, allowed to determine the effective moment. Friction parameters can be 
determined using methods presented in [40;41]. With the torque course available, the angular crankshaft speed values could be determined:

$$
\omega_{i}= \begin{cases}\sqrt{\omega_{i-1}^{2}-\frac{2 T_{r} \Delta C A}{J_{E}^{\Sigma}} ;} & T_{r} \leq M I T \\ \sqrt{\omega_{i-1}^{2}+\frac{2 T_{r} \Delta C A}{J_{E}^{\Sigma}} ;} & T_{r}>M I T\end{cases}
$$

where $\triangle C A-$ increase of thecrankshaft angle degrees, deg;

The mass moment of inertia of the rotating elements of the engine:

$$
J_{E}^{\Sigma}=J_{c}+0.64 m_{B} R^{2}
$$

where glossary - see Table 1.

To determine the angular crankshaft speed $\omega$ from (4), the mean indicated torque MIT in the cycle had to be determined, which was not possible without calculating the whole cycle. This problem has been solved by repeating the calculations, what is described further in this paper.

In the pneumatic part, the assumptions were adopted:

- the air was regarded as a thermodynamically ideal gas, while being viscous and compressible;

- the flow took place without internal friction and heat exchange with the surroundings;

- the state of the air was constant in a given volume and depended on time;

- the joints of the individual elements of the tested object were perfectly airtight;

- the air properties were assumed to be uniform both in the local volume and in the entire crosssection of the flow through the local resistance;

- the air temperature was constant in the process.

Using the principle of mass conservation and lumped element methods, the change in the pressure of the air in the variable concentrated volume considering the isentropic flow through local drags was presented as:

$$
\frac{\mathrm{d} p_{c}}{\mathrm{~d} t}=\frac{\kappa R_{g} T_{g}}{V_{c}}\left(\dot{m}_{\text {in }}-\dot{m}_{\text {out }}-\frac{p_{c}}{R_{g} T_{g}} \frac{\mathrm{d} V_{c}}{\mathrm{~d} t}\right)
$$

Where the air mass flow:

$$
\begin{gathered}
\dot{m}_{\text {in }}=\frac{\mathrm{d} m_{\text {in }}}{\mathrm{d} t}=(\mu A)_{\text {in }} \frac{p_{\text {in }}}{\sqrt{R_{g} T_{g}}} \psi_{\text {max }} b \frac{p_{\text {in }}-p_{c}}{b p_{\text {in }}-p_{c}} \\
\dot{m}_{\text {out }}=\frac{\mathrm{d} m_{\text {out }}}{\mathrm{d} t}=(\mu A)_{\text {out }} \frac{p_{c}}{\sqrt{R_{g} T_{g}}} \psi_{\text {max }} b \frac{p_{c}-p_{a}}{b p_{c}-p_{a}}
\end{gathered}
$$

where glossary - see Table 1 and Table 2 .

In order to initiate the calculations, it was necessary to specify the input parameters and the initial conditions, which are presented in Table 2.

Table 2

Necessary to specify input parameters and boundary conditions of simulation

\begin{tabular}{|r|c|c|r|}
\hline \multicolumn{1}{|c|}{ Parameter } & Glossary & Unit & \multicolumn{1}{|c|}{ Value } \\
\hline inlet pressure & $p_{\text {in }}$ & $\mathrm{Pa}$ & $10 \mathrm{e} 5$ \\
\hline atmospheric pressure & $p_{a}$ & $\mathrm{~Pa}$ & $1 \mathrm{e} 5$ \\
\hline air temperature & $T_{g}$ & $\mathrm{~K}$ & 293.15 \\
\hline adiabatic exponent & $\kappa$ & - & 1.4 \\
\hline gas constant & $R_{g}$ & $\mathrm{~J} \cdot(\mathrm{kg} \cdot \mathrm{K})^{-1}$ & 287.15 \\
\hline max. value of theSt' Venant and Wanzel function & $\psi_{\max }$ & - & 0.578 \\
\hline
\end{tabular}


Table 1 (continued)

\begin{tabular}{|c|c|c|c|}
\hline Parameter & Glossary & Unit & Value \\
\hline factor of the Metlyuk-Avtushko function & $b$ & - & 1.13 \\
\hline throughput of the timing system & \multicolumn{3}{|c|}{ see Fig. 3 and Fig. 4.} \\
\hline \multicolumn{4}{|c|}{ Boundary conditions of simulation for $t=0 \mathrm{~s}$} \\
\hline crankshaft angle degrees & $C A$ & $\operatorname{deg}$ & 0 \\
\hline displacement of pistons & $x$ & $\mathrm{~m}$ & 0 \\
\hline volume of cylinder: combustion chamber & $V_{c}=V_{\min }$ & $\mathrm{m}^{3}$ & $0.1096 \mathrm{e}-6$ \\
\hline pressure in cylinder & $p_{c}$ & $\mathrm{~Pa}$ & $f\left(T_{r}, \omega\right)$ \\
\hline timing system & $\begin{array}{l}(\mu A)_{\text {in }} \\
(\mu A)_{\text {out }}\end{array}$ & $\mathrm{m}^{2}$ & $\begin{array}{r}\text { variants } \\
0 \text { (Fig. 4) } \\
\end{array}$ \\
\hline number of cycles analysing for determining & - & - & 10 \\
\hline
\end{tabular}

In the study, a solenoid valve $2 \mathrm{M}-15$ 1/2 $0-16$ bar with the flow diameter $d_{v}=4.5 \mathrm{~mm}$ was used for realizing the inlet process. Regarding the lack of available opening and closing characteristics of the valve, the characteristics of the gas injector, which has a similar design, were taken as a base. According to the available literature [42-45], the course of opening and closing of the inlet valve as a function of time $t$ in throughput absolute values was described in relation [35]:

$$
\frac{(\mu A)}{(\mu A)_{\max }}(t)=\left\{\begin{array}{l}
\frac{1}{t_{o}^{2}} t^{2} ; \quad 0 \leq t<0 \\
1 ; \quad t_{o} \leq t<t_{o}+t_{f_{o}} \\
-\frac{1}{t_{c}^{2}} t^{2}+1 ; t_{o}+t_{f o}<t \leq t_{\text {inlet }}
\end{array}\right.
$$

The control parameter for the inlet valve was the time of the $t_{\text {impulse }}$ control pulse.In equation (9), the parameters that affected the opening process were: opening time $t_{o}$, closing time $t_{c}$, full open time $t_{f o}$ and the resulting inlet time $t_{\text {inlet }}$. With the specified valve control pulse time $t_{\text {imp }}$ (Fig. 3 ), the $t_{\text {inlet }}$ time was increased due to $t_{c}$. The process of opening the valve was described as a function of time, therefore, the process in respect to the angle of rotation of the crankshaft was determined by the angular crankshaft speed.

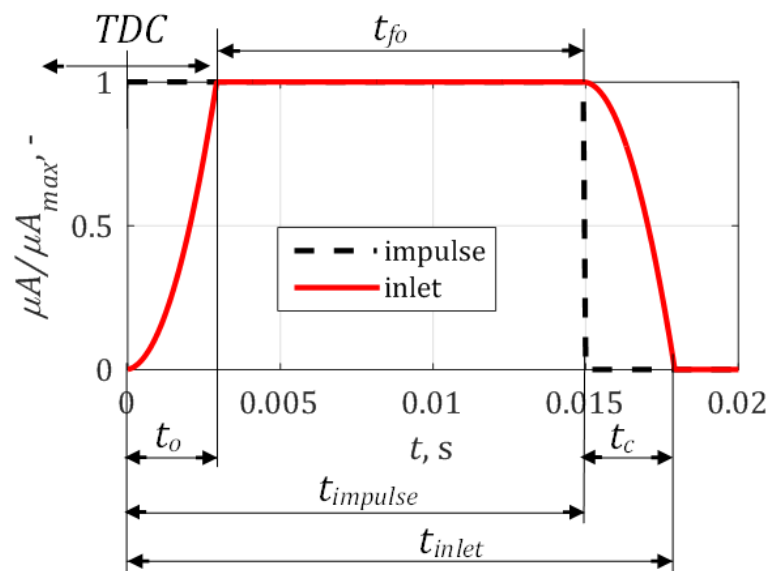

Fig. 3. Example course of the inlet process as a time function (description in the main text)

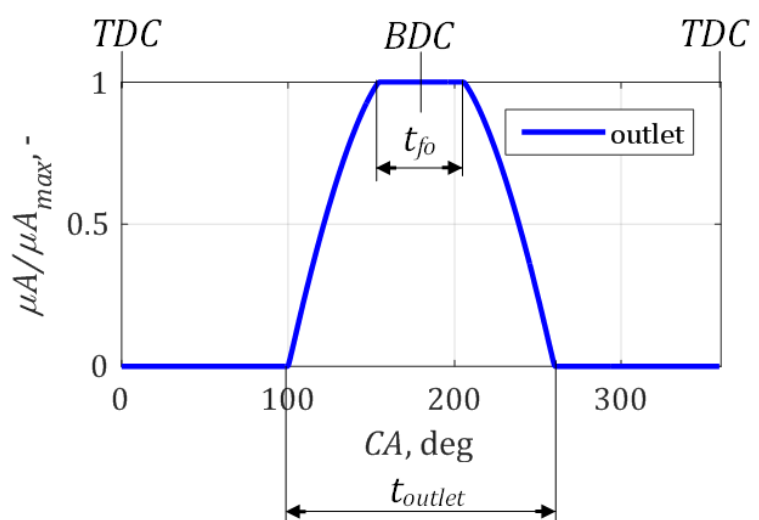

Fig. 4. Course of the outlet process as a crankshaft rotation angle function (description in the main text)

The course of the opening of the outlet window in the $C A$ function was determined from the CAD model of the engine (SolidWorks). Fig.4 presents the course of the opening of the outlet window, additionally marking the angle of the outlet $\alpha_{o u t l e t}$ and the angle of the full opening $\alpha_{f o}$.

The operation of the inlet valve shown in Fig. 3 was based on a solution with an electromagnet. In order to shorten the valve opening and closing time, piezoelectric actuators should be used [46-49]. 


\section{Results and discussion}

The simulations were carried out using the Matlab-Simulink environment. The differential equation (6) was solved numerically with the implicit trapezoidal method combined with reverse differentiation. The equation was solved as a function of time, therefore it was necessary to interpolate the inlet valve and the outlet window operation data. The outlet window in each calculation was permanently associated to $C A$, however, the operation of the inlet valve was time dependent and at different angular crankshaft speeds covered a different part of the operating cycle.

In the description of the calculation results the speed was operated:

$$
n=\frac{\omega}{2 \pi}
$$

As mentioned above, the initial MIT and $p_{\text {cstart }}$ had to be determined for the calculations. Consequently, in the calculation, the first simulation for 10 cycles was performed assuming initial conditions $M I T=0 \mathrm{Nm}$ and $p_{c s t a r t}=p_{a}$, taking into account that the first cycle was incomplete. Subsequently, MIT and $p_{\text {cstart }}$ values from the last cycle were calculated and replaced again as initial conditions. The second cycle of the simulation was considered to be correct and the results were obtained from this cycle. The general principle adopted in the calculation was to take the average rotational speed and the timing system conditions and to search for answers in the cylinder pressure, torque and speed runs (Fig. 5). On that basis, the MIP and $\mathrm{d} m / \mathrm{d} t$ were determined.
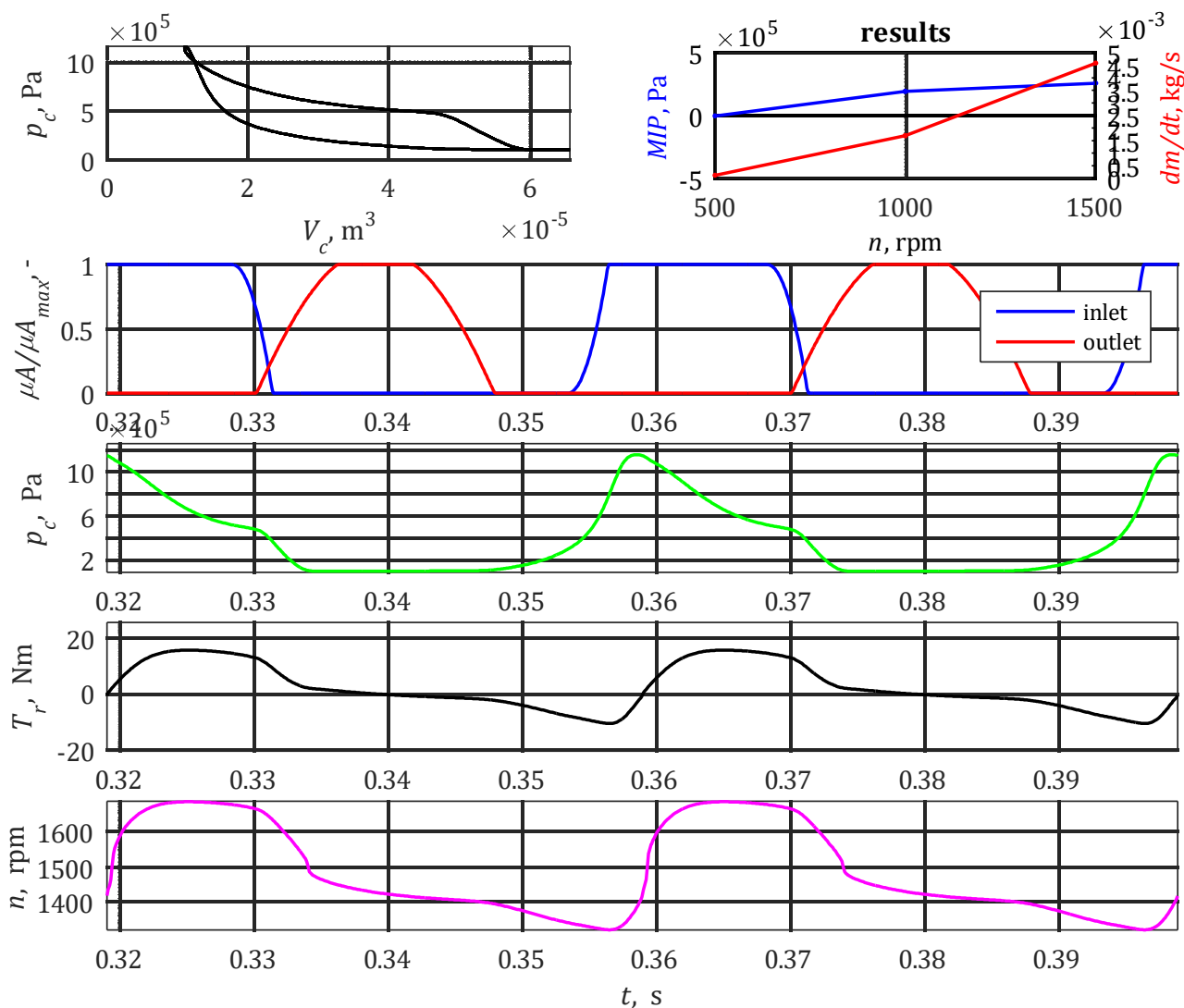

Fig. 5. Example of calculation results ( 2 cycles, $1500 \mathrm{rpm}, I V O=50 \mathrm{deg} B T D C)$

The simulations were performed according to the scenario presented in Table 3.

Table 3

Variants of simulation

\begin{tabular}{|c|c|c|c|c|c|}
\hline \multicolumn{2}{|c|}{$I V O, \operatorname{deg} \backslash n, \mathrm{rpm}$} & 500 & 1000 & - & 3500 \\
\hline-50 & 50 BTDC & \multirow{4}{*}{\multicolumn{4}{|c|}{$\begin{array}{c}t_{\text {impulse }}=15 \mathrm{~ms} \\
t_{o}=3 \mathrm{~ms} \\
t_{c}=3 \mathrm{~ms} \\
\text { DC - before TDC; ATDC - after TDC }\end{array}$}} \\
\hline-40 & 40 B TDC & & & & \\
\hline - & - & & & & \\
\hline 50 & 50 ATDC & & & & \\
\hline
\end{tabular}


Comparing the results of the calculations (Fig. 6), a significant variation in $M I P$ values was visible, depending on $n$ and IVO. Maximum MIP values were reached at $n=500 \mathrm{rpm}$ and $I V O=20$ deg BTDC. The indicated pressure decreased with the $n$ growth. A negative effect of $I V O$ on BTDC for (500 and 1000) rpm was observed. The reason for this was the counter pressure from the inlet system during the compression stroke and a significant drop in MIP. At $3500 \mathrm{rpm}$ and $I V O=(20-$ 50) deg ATDC, the indicated pressure dropped to $0 \mathrm{~Pa}$, what means that the power supply became a resistance during the engine operation and did not generate any torque. Although a slightly different engine model and deviating boundary conditions were used in the calculations, the tendencies of the obtained values are approximate to the results of other researchers $[25 ; 34 ; 35]$, therefore they could be considered as correct.

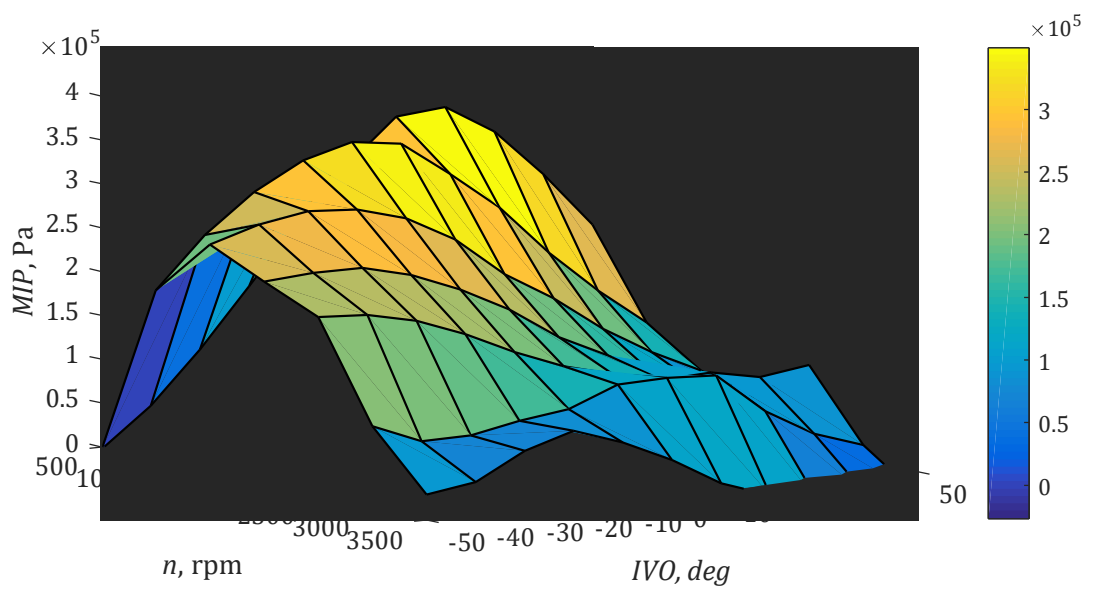

Fig. 6. Results of the simulation - mean indicated pressure

Analysing the results of the air mass flow $(\mathrm{d} m / \mathrm{d} t)$, a proportional increase was seen as the rotational speed increased. In turn, IVO did not significantly differentiate the air mass flow, beyond the range (20-50) deg ATDC at higher rotational speeds, where, as it was mentioned earlier, no torque was generated and the cylinder filling was limited due to the compression process.

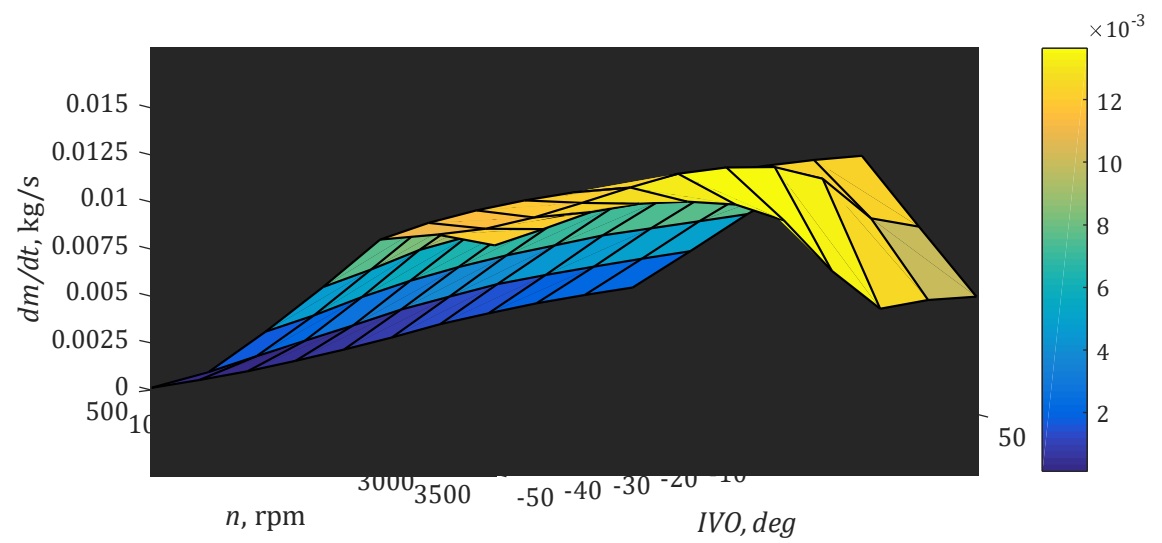

Fig. 7. Results of the simulation - air mass flow

a)

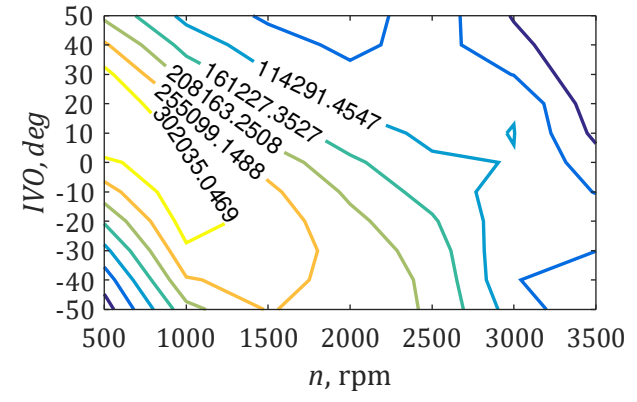

b)

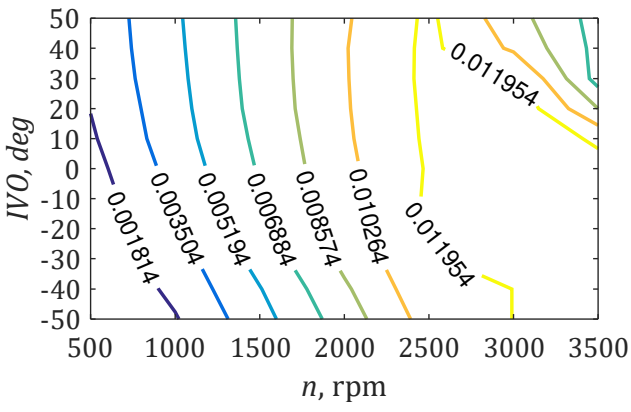

Fig. 8. Contour plots of determined parameters: $a-M I P ; b-d m / d t$ 
In order to better illustrate the results of the calculations, the contour plots were prepared (Fig. 8). The most efficient engine operating range with $M I P$ of $3 \mathrm{e} 5 \mathrm{~Pa}$ was $n=(500-1500) \mathrm{rpm}$ and $I V O=(-30-30) \mathrm{deg}$. There was also a reduced air mass flow of about $0.003 \mathrm{~kg} \cdot \mathrm{s}^{-1}$. The range $n=(2500-3500) \mathrm{rpm}$ was characterised by reduced indicated pressure and high air mass flow $\left(0.012 \mathrm{~kg} \cdot \mathrm{s}^{-1}\right)$.

The presented results of the simulation concerned $I V O$ and $n$ variants with a constant value of the inlet time $t_{\text {inlet }}=15 \mathrm{~ms}$, which had a major impact on the air mass flow. In a further step, it was planned to run a series of simulations with variable $t_{\text {inlet }}$ to minimize the air mass flow and to regulate the intermediate states of the engine operation.

\section{Conclusions}

The article presents the analysis of the influence of selected parameters of the timing system on the indicated pressure in the cylinder of the pneumatic engine. The base engine was a two-stroke Jawa 50 combustion engine, which was subjected to modifications necessary to supply compressed air. The engine was operated as two-stroke with an outlet system in the form of the original window, while the intake was realized through the solenoid valve. The analysis had a computational character and was based on the own mathematical model divided into the mechanical and the pneumatic parts. The angle of the inlet valve opening was specified as the control parameter, the value of which was differentiated with respect to the top dead centre. The remaining inlet parameters were constant. The first of the determined values is a utility indicator and the second is an economic indicator. The analysis showed that the engine reaches the maximum mean indicated pressure of approximately 3 e5 $\mathrm{Pa}$ at (500-1000) rpm and inlet valve opening (0-20) deg before the top dead centre. The ranges where the engine is not efficient and not able to operate stably were shown. The research revealed also a proportional increase in the air mass flow as the rotational speed increases, with minor variation from the inlet valve opening. In the study, a constant value of the inlet time was assumed, what affected the air mass flow, therefore further studies were planned to assess the impact of differentiation of this parameter.

\section{Funding}

This publication was financed through the program of the Ministry of Science and Higher Education of Poland named "Regional Initiative of Excellence" in 2019-2022 project number 011/RID/2018/19.

\section{Acknowledgements}

This research was co-founded through the subsidy of the Ministry of Science and Higher Education for the discipline of Mechanical Engineering at the Faculty of Mechanical Engineering, Bialystok University of Technology.

\section{References}

[1] WLTP lab test. [online] [10.11.2019]. Available at: http://wltpfacts.eu/.

[2] Commission Regulation (EU) 2017/1154 of 7 June 2017 amending Regulation (EU) 2017/1151 supplementing Regulation (EC) No 715/2007 of the European Parliament and of the Council on type-approval of motor vehicles with respect to emissions from light passenger and commercial vehicles (Euro 5 and Euro 6) and on access to vehicle repair and maintenance information, amending Directive 2007/46/EC of the European Parliament and of the Council, Commission Regulation (EC) No 692/2008 and Commission Regulation (EU) No 1230/2012 and repealing Regulation (EC) No 692/2008 and Directive 2007/46/EC of the European Parliament and of the Council as regards real-driving emissions from light passenger and commercial vehicles (Euro 6). Official Journal of the European Union, L175, 7.7.2017, 708 p.

[3] Walus K.J., Wargula L., Krawiec P., Adamiec J.M. Legal regulations of restrictions of air pollution made by non-road mobile machinery - the case study for Europe: a review. Environmental Science and Pollution Research, vol. 25(4), 2018, pp. 3243-3259. 
[4] Wargula L., Walus K.J., Krawiec P. Small engines spark ignited (SI) for non-road mobile machinery - review. Proceedings of 22nd International Scientific Conference "Transport Means 2018", T.2, 2018, pp. 585-591.

[5] Onishi S., Jo S.H., Shoda K., Jo P.D., Kato S. Active thermo-atmosphere combustion (A.T.A.C.) A new combustion process for internal combustion engines. SAE Paper, 790501, 1979.

[6] Jeuland N., Montagne X., Duret P. New HCCI/CAI combustion process development: Methodology for determination of relevant fuel parameters. Oil \& Gas Science and Technology, vol. 59(6), 2004, pp. 571-579.

[7] Mikulski M., Balakrishnan P.R., Doosje E., Bekdemir C. Variable valve actuation strategies for better efficiency load range and thermal management in an RCCI engine. SAE Technical Papers, 2018-01-0254, 2018, $14 \mathrm{p}$.

[8] Fox J.T., Yang K., HunsickerR. Diesel particulate filter cleaning effectiveness: estimated ash loading, quantified particulate removal, and post-cleaning filter pressure drop. Emission Control Science and Technology, 2019, pp. 1-11 (on-line).

[9] Senthil Kumar J., Ramesh Bapu B.R., Sivasaravanan S., Prabhu M., Abubacker M.A. Experimental studies on emission reduction in DI Diesel engine by using nano catalyst coated catalytic converter. International Journal of Ambient Energy, 2019, pp. 1-17 (on-line).

[10] Resitoglu I.A., Altinisik K., Keskin A., Ocakoglu K. The effects of Fe2O3 based DOC and SCR catalyst on the exhaust emissions of diesel engines. Fuel, vol. 262, 2020, 116501.

[11] Raslavicius L., Kersys A., Mockus S. Kersiene N., Starevicius M. Liquefied petroleum gas (LPG) as a medium-term option in the transition to sustainable fuels and transport. Renewable \& Sustainable Energy Reviews, vol. 32, 2014, pp. 513-525.

[12] Borawski A. Modification of a fourth generation LPG installation improving the power supply to a spark ignition engine. Eksploatacja i Niezawodnosc - Maintenance and Reliability, vol. 17(1), 2015, pp. 1-6.

[13] Mikulski M., Wierzbicki S., Pietak A. Numerical studies on controlling gaseous fuel combustion by managing the combustion process of diesel pilot dose in a dual-fuel engine. Chemical and Process Engineering - InzynieriaChemiczna i Procesowa, vol. 36 (2), 2015, pp. 225-238.

[14] Pulawski G., Szpica D. The modelling of operation of the compression ignition engine powered with diesel fuel with LPG admixture. Mechanika, vol. 21(6), 2015. pp. 501-506.

[15] Dimitrova Z., Marechal F. Gasoline hybrid pneumatic engine for efficient vehicle powertrain hybridization. Applied Energy, vol. 151, 2015, pp. 168-177.

[16] Raslavicius L., Kersys A. Makaras R. Management of hybrid powertrain dynamics and energy consumption for 2WD, 4WD, and HMMWV vehicles. Renewable and Sustainable Energy Reviews, vol. 68(1), 2017, pp. 380-396.

[17] Grigor'ev M.A., Naumovich N.I., Belousov E.V. A traction electric drive for electric cars. Russian Electrical Engineering, vol. 86(12), 2015, pp. 731-734.

[18] Simon M. Pneumatic vehicle, research and design. Procedia Engineering, vol. 181, 2017, pp. 200205.

[19] Mathison S., Harty R., Cohen J., Gupta N.,Sato H. Application of MC Method-Based H2 Fueling. SAE Technical Paper 2012-01-1223, 2012, 12 p.

[20] Yangbo D., Xi J., Fengmin S. Combustion Characteristics of Advanced Vortex Combustor Burning H2 Fuel. ASME 2014 International Mechanical Engineering Congress and Exposition, V08AT10A013, 2014.

[21] Mitianiec W. Pneumatic two-stroke engine as an alternative power source. Journal of KONES Powertrain and Transport, vol. 15(3), 2008, pp. 357-366.

[22] Allam S., Zakaria M. Experimental investigation of compressed air engine performance. International Journal of Engineering Inventions, vol. 7(1), 2018, pp. 13-20.

[23] Badr O., Probert S.D., O'Callaghan P.W. Multi-vane expanders: internal-leakage losses. Applied Energy, vol. 20(1), 1985, pp. 1-46.

[24]Librovich B.V., Nowakowski A.F. Analysis, design, and modeling of a rotary vane engine (RVE). Journal of Mechanical Design, vol. 126(4), 2004, pp. 711-720.

[25] Dvorak L., Fojtasek K., Rehacek V. Calculations of parameters and mathematical model of rotary air motor. EPJ Web of Conferences, 143 02018, 2017, 4 p.

[26]Zwierzchowski J. Design type air engine Di Pietro. EPJ Web Conferences, 143 02149, 2017, 6 p. 
[27] MDi pneumatic engine [online] [10.11.2019]. Available at: https://www.mdi.lu/.

[28] Engineair pneumatic engine [online] [10.11.2019]. Available at: http://www.engineair.com.au/.

[29] Michael M., Voser C., Onder C., Guzzella L. Design methodology of camshaft driven charge valves for pneumatic engine starts. IFAC Proceedings, vol. 45(30), 2012, pp. 33-40.

[30] Kalekin V.S., Kalekin D.V., NefedchenkoA.N. A Mathematical model of a piston pneumatic engine with self-acting air distribution. Chemical and Petroleum Engineering, vol. 50(1-2), 2014, pp. 91-98.

[31] Semenchukova V., Grishin Y., Malastowski N. Mathematical modeling of a piston engine pneumatic start. International Russian Automation Conference (RusAutoCon), 2018, pp. 1-4.

[32] Huang Ch.-Y., Hu Ch.-K., Yu C.-J., Sung Ch-.S. Experimental investigation on the performance of a compressed-air driven piston engine. Energies, vol. 6, 2013, pp. 1731-1745.

[33]Fang Y.D., Lu Y.J., Yu X.L., Roskilly A.P. Experimental study of a pneumatic engine with heat supply to improve the overall performance. Applied Thermal Engineering, vol. 134, 2018, pp. 7885.

[34] Brejaud P., Higelin P., Charlet A., Colin G., Chamaillard Y. Convective heat transfer in a pneumatic hybrid engine. Oil \& Gas Science and Technology, vol. 66(6), 2011, pp. 1035-1051.

[35] Szpica D., Korbut M. Modelling methodology of piston pneumatic air engine operation. ActaMechanica et Automatica, vo. 13/4(50), 2019, pp. 271-278.

[36] Jawa 50 technical data [online] [10.11.2019]. Available at: http://www.jawa-50.cz/clanek/jawa23-mustang-technicke-udaje.html.

[37] Szpica D. Modelling of the operation of a Dual Mass Flywheel (DMF) for different engine-related distortions. Mathematical and Computer Modelling of Dynamical Systems, vol. 24(6), 2018, pp. 643-660.

[38] Kaminski Z. Experimental and numerical studies of mechanical subsystem for simulation of agricultural trailer air braking systems. International Journal of Heavy Vehicle System, vol. 20(4), 2013, pp. 289-311.

[39] Kaminski Z. Mathematical modelling of the trailer brake control valve for simulation of the air brake system of farm tractors equipped with hydraulically actuated brakes. Eksploatacja i Niezawodnosc - Maintenance and Reliability, vol. 16(4), 2014, pp. 637-643.

[40] Borawski A. Common methods in analysing the tribological properties of brake pads and discs - a review. ActaMechanica et Automatica, vol. 13(3), 2019, pp. 189-199.

[41]Borawski A. Suggested research method for testing selected tribological properties of friction components in vehicle braking systems. ActaMechanica et Automatica, vol. 10(3), 2016, pp. 223226.

[42] Duk M., Czarnigowski J. The method for indirect identification gas injector opening delay time. PrzegladElektrotechniczny, vol. 88(10b), 2012, pp. 59-63.

[43] Czarnigowski J. Teoretyczno-empiryczne studium modelowania impulsowego wtryskiwacza gazu. Lublin: PolitechnikaLubelska, 2012, 194 p. (In Polish).

[44] Szpica D. The influence of selected adjustment parameters on the operation of LPG vapor phase pulse injectors. Journal of Natural Gas Science and Engineering, vol. 34, 2016, pp. 127-1136.

[45] Szpica D. Research on the influence of LPG/CNG injector outlet nozzle diameter on uneven fuel dosage. Transport, vol. 33(1), 2018, pp. 186-196.

[46] Mieczkowski G. Stress fields at the tip of a sharp inclusion on the interface of a bimaterial. Mechanics of Composite Materials vol. 52(5), 2016, pp. 601-610.

[47] Mieczkowski G. Optimization and prediction of durability and utility features of three-layer piezoelectric transducers. Mechanika, vol. 24(3), 2018, pp. 335-342.

[48] Mieczkowski G. Criterion for crack initiation from notch located at the interface of bi-material structure. Eksploatacja i Niezawodnosc - Maintenance and Reliability, vol. 21(2), 2019, pp. 301310.

[49] Mieczkowski G., Borawski A., Szpica D. Static electromechanical characteristic of a three-layer circular piezoelectric transducer, Sensors, vol. 20, 2020, 222, 14 p. 